\title{
SISTEM INFORMASI PEMBAYARAN BIAYA SEKOLAH PADA SD AR-RAUDAH BANDAR LAMPUNG
}

\author{
Damayanti $^{1)}$, Heni Sulistiani ${ }^{2)}$ \\ ${ }^{1,2)}$ Sistem Informasi, Universitas Teknokrat Indonesia \\ Jl. H.ZA Pagaralam, No 9-11, Labuhanratu,Bandarlampung \\ Email:damayanti@teknokrat.ac.id ${ }^{l)}$, henisulistiani@teknokrat.ac.id ${ }^{2)}$
}

\begin{abstract}
Abstrak
Sekolah Dasar Ar-Raudah merupakan salah satu Sekolah Dasar Islam Terpadu di Bandar Lampung yang beralokasi di jalan Tamin No. 68 Bandar Lampung. Untuk kelancaran proses pembelajaran di Sekolah Dasar Ar-Raudah, diperlukan sumber dana yang salah satunya adalah sumber dana dari pembayaran biaya pendidikan yang diperoleh dari siswa.
\end{abstract}

Sistem pembayaran biaya sekolah pada SD Ar-Raudah Bandar Lampung masih menggunakan pencatatan kebuku besar kemudian di-inputkan ke program microsoft Excel, sehingga sering terjadi kesalahan transaksi pencatatan dan pembuatan laporan yang belum efektif, serta kurangnya keamanan data. Metode pengembangan sistem yang digunakan adalah waterfall dan bahasa pemprograman delphi 7.0 dengan database destop atau paradox.

Tujuan penelitian ini adalah untuk membangun sistem informasi pembayaran biaya sekolah pada SD ArRaudah Bandar Lampung agar menjadi lebih baik dan mempermudah petugas yang berwenang dalam pembuatan laporan sehingga mempercepat pimpinan dalam pengambilan keputusan.

Kata kunci :Sistem Informasi, Biaya Sekolah,Delphi 7, Paradox

\section{Pendahuluan}

\subsection{Latar Belakang}

Perkembangan teknologi merupakan serangkaian kegiatan yang dilaksanakan secara berkesinambungan dan bertujuan untuk mencapai suatu keadaan atau kondisi yang lebih baik dari sebelumnya. Pada saat ini peradaban dunia telah menunjukkan adanya perkembangan teknologi, seiring dengan kemajuan teknologi tersebut, manusia dituntut untuk bekerja dengan lebih efektif dan efisien guna memperoleh hasil yang lebih cepat, tepat dan akurat. Teknologi komputerisasi dapat mempermudah dan mempercepat pengolahan data, yang salah satunya dalam pencatatan pembayaran biaya sekolah, sehingga menjadi suatu informasi yang dibutuhkan oleh semua pihak, terutama untuk kegiatan operasional pendidikan di sekolah.

Sistem informasi memberikan nilai tambah terhadap proses, produksi, kualitas, manajemen, pengambilan keputusan dan pemecahan masalah serta keunggulan kompetitif yang berguna bagi kegiatan bisnis [3]. Sistem manual dalam pencatatan biaya sekolah tidak selamanya mampu mengatasi permasalahan-permasalahan yang dihadapi, banyaknya data-data yang ada dalam perusahaan menyebabkan berbagai macam masalah dalam pencatatan pembayaran biaya sekolah seperti: kesulitan pencarian data, lambatnya penyajian laporan, dan kurangnya keamanan data. Sistem informasi pembayaran biaya sekolah merupakan salah satu cara yang tepat untuk mengatasi segala permasalahan tersebut, karena dapat meningkatkan efektifitas dan efisiensi kerja dalam kegiatan penerimaan pembayaran biaya sekolah untuk memperoleh informasi-informasi yang dibutuhkan. Aplikasi yang dibangun sangat membantu admin untuk melakukan proses pengadministrasian pembayaran biaya Sekolah Siswa [5].

Sekolah Dasar Ar-Raudah merupakan salah satu Sekolah Dasar Islam Terpadu di Bandar Lampung yang berlokasi di jalan Tamin No. 68 Bandar Lampung. Sistem pembayaran biaya sekolah pada SD Ar-Raudah saat ini belum menerapkan sistem informasi pembayaran biaya sekolah secara optimal, karena dalam pengolahan pembayaran biaya sekolah masih menggunakan program microsoft excel, sehingga pembuatan laporan penerimaan kas yang kurang efektif dan belum ada keamanan pada sistem. Berdasarkan permasalahan tersebut, maka perlu adanya sistem informasi pembayaran biaya sekolah dengan menggunakan program aplikasi bahasa pemrograman delphi, agar dapat mengerjakan penerimaaan pembayaran biaya sekolah menjadi lebih mudah dan lebih baik.

\subsection{Rumusan Masalah}

Berdasarkan latar belakang yang telah diuraikan maka dapat dirumuskan masalah yaitu bagaimana membangun sistem informasi pembayaran biaya sekolah pada SD ArRaudah Bandar Lampung yang dapat menyajikan laporan yang efektif dan efisien.

\subsection{Tujuan Penelitian}

Adapun tujuan dari penelitian ini untuk membangun sistem informasi pembayaran biaya sekolah pada SD ArRaudah Bandar Lampung.

\subsection{Metode Penelitian}

Metode pengumpulan data yang penulis gunakan yaitu metode wawancara (interview), pengamatan (observasi), dan studi kepustakaan, serta menggunakan metode pengembangan sistem waterfall dengan tahapan-tahapan yang terdiri dari analisis, desaian, implementasi, 
pengujian dan perawatan [2]. Tahapan-tahapan dalam model waterfall adalah sebagai berikut:

1. Analisis

Tahap ini adalah tahap mengidentifikasi kebutuhan termasuk kegunaan software yang diharapkan pengguna. Informasi ini diperoleh melalui wawancara, observasi atau pengamatan. Informasi tersebut dianalisis untuk mendapatkan dokumentasi kebutuhan pengguna untuk digunakan pada tahap selanjutnya

2. Desain

Tahap ini dilakukan sebelum melakukan coding. Tahap ini bertujuan untuk memberikan gambaran apa yang seharusnya dikerjakan dan bagaimana tampilannya. Tahap ini membantu dalam menspesifikasikan kebutuhan hardware dan sistem serta mendefinisikan arsitektur sistem secara keseluruhan.

3. Implementasi

Pada tahap ini melakukan pembuatan program atau software sistem informasi pembayaran biaya sekolah pada SD Ar-Raudah Bandar Lampung.

4. Pengujian.

Tahap pengujian dilakukan untuk mengetahui apakah software yang dibuat telah sesuai dengan desainnya dan masih terdapat kesalahan atau tidak.

5. Perawatan.

Tahap perawatan merupakan tahap terakhir dalam model waterfall. Software yang sudah jadi dijalankan serta dilakukan pemeliharaan. Pemeliharaan termasuk dalam memperbaiki kesalahan yang tidak ditemukan pada langkah sebelumnya.

\subsection{Kajian Pustaka}

\subsubsection{Sistem}

Sistem adalah sekumpulan hal atau kegiatan atau elemen atau subsistem yang saling bekerja sama atau yang dihubungkan dengan cara-cara tertentu sehingga membentuk satu kesatuan untuk melaksanakan suatu fungsi guna mencapai suatu tujuan [6].

\subsubsection{Sistem informasi}

Sistem informasi adalah suatu sistem didalam suatu organisasi yang mempertemukan kebutuhan pengolahan transaksi harian, mendukung operasi, bersifat manajerial dan kegiatan strategi dari suatu organisasi dan menyediakan pihak luar tertentu dengan laporan-laporan yang diperlukan [2].

\subsubsection{Pembayaran Biaya Sekolah}

Pembayaran biaya sekolah merupakan sumbangan yang dikenakan kepada siswa untuk digunakan bagi keperluan penyelenggarakan dan pembinaan pendidikan. Rincian biaya sekolah terdiri dari biaya seragam, biaya asruransi, biaya ekstrakurikulum, biaya bangunan, biaya iuran ITWAR, dan biaya SPP.

\section{Pembahasan}

\subsection{Analisis}

Sistem pembayaran biaya sekolah pada SD Ar-Raudah Bandar Lampung masih melakukan pencatatan kebuku besar kemudian di-inputkan ke program microsoft Excel mengakibatkan sering terjadi kesalahan transaksi pencatatan dan pembuatan laporan yang belum efektif, serta kurangnya keamanan data. Hal ini dapat mengakibatkan pelaporan penerimaan pembayaran biaya sekolah kepada pimpinan menjadi lama, sehingga menghambat pimpinan dalam mengambil keputusan. Selain itu juga belum ada kemanan pada sistem sehingga data rentan disalahgunakan oleh pihak yang tidak berwenang. Maka proses penerimaan pembayaran biaya sekolah pada SD Ar-Raudah perlu dibangun sistem aplikasi agar lebih baik, dan mempermudah petugas dalam pembuatan laporan. Perancangan sistem yang digunakan adalah sebagai berikut:

\subsection{Desain}

\subsubsection{Diagram Konteks (Context Diagram) Penerimaan Kas}

Pada diagram konteks sistem pembayaran biaya sekolah terdiri dari 3 entitas yaitu : administrasi, siswa dan pimpinan. Diagram konteks dapat dilihat pada gambar 1 . di bawah ini:

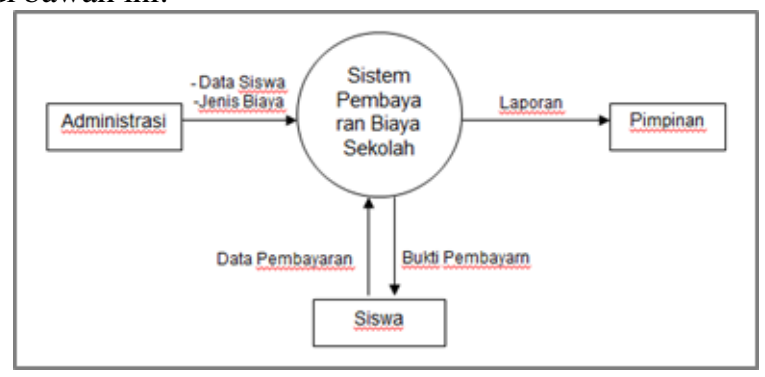

Gambar 1. Diagram Konteks (Context Diagram)

\subsubsection{Diagram Alir Data (Data Flow Diagram) Level 0}

Diagram alir data level 0 dapat dilihat pada gambar 2 di bawah ini:

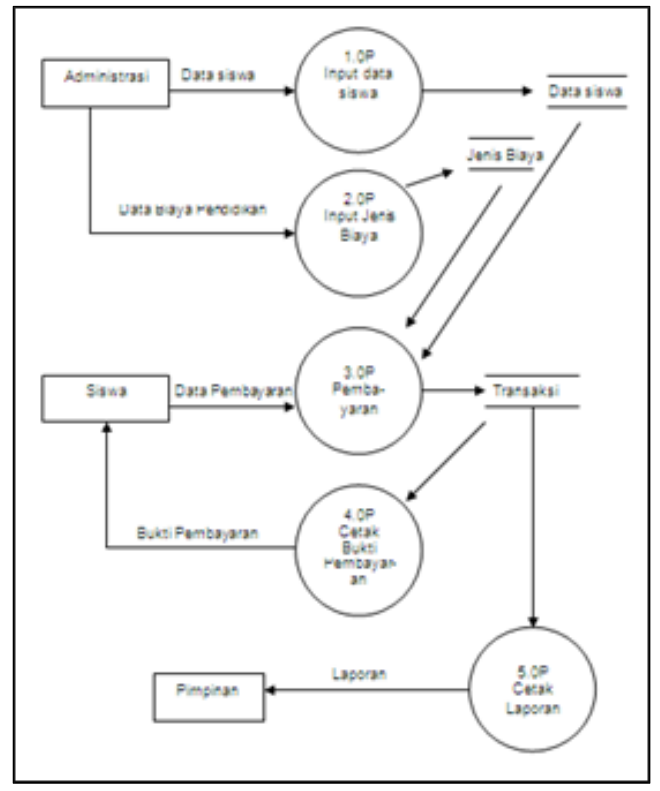

Gambar 2. Diagram Alir Data Level 0 


\subsubsection{Entity Relationship Diagram (ERD)}

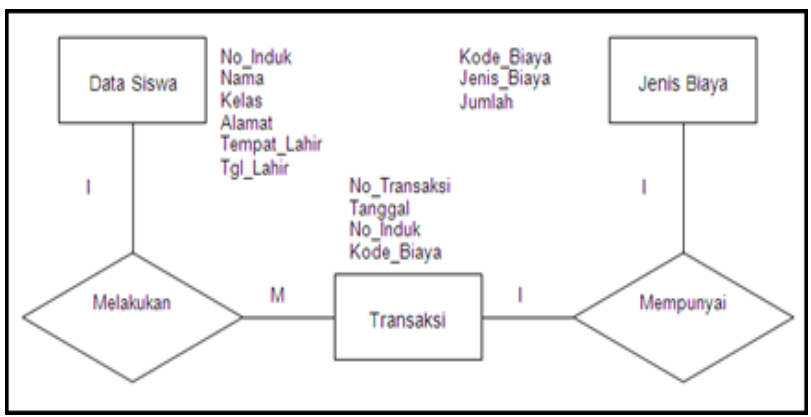

Gambar 3. Entity Relationship Diaam (ERD)

\subsubsection{Relasi Antar Tabel}

Relasi antar tabel dari perancangan sistem pembayaran biaya sekolah dapat dilihat pada gambar 4 di bawah ini:

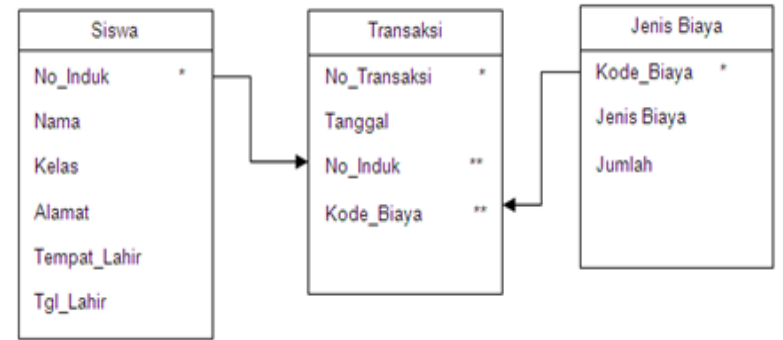

Gambar 4. Relasi Antar Tabel

\subsection{Implementasi Sistem}

\subsubsection{Menu Password}

Menu password merupakan tampilan awal untuk masuk ke menu utama dengan mengisi user name dan password, setelah itu pilih Ok. Bila dalam pengisian user name dan password tidak sesuai dengan seharusnya maka program tidak akan menampilkan form menu utama. Tombol keluar digunakan untuk keluar dari menu password. Menu pasword digunakan untuk keamanan sistem. Adapun tampilan menu pasword dapat dilihat pada gambar 6. dibawah ini :

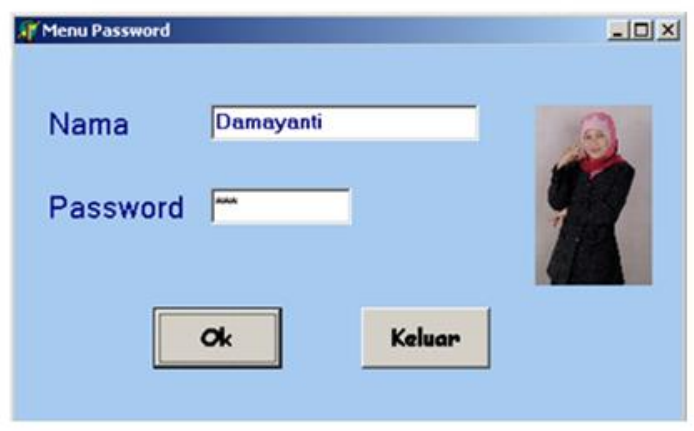

Gambar 6. Menu Fassword

\subsubsection{Form Menu Utama}

Pada form menu utama terdiri dari sub menu input, transaksi, cari dan laporan. Sub menu input terdapat input data siswa, input data jenis biaya. Sub menu transaksi adalah menu transaksi proses pembayaran. Sedangkan sub menu laporan adalah sub menu laporan pembayaraan. Tampilan menu utama dapat dilihat pada gambar 7. dibawah ini :

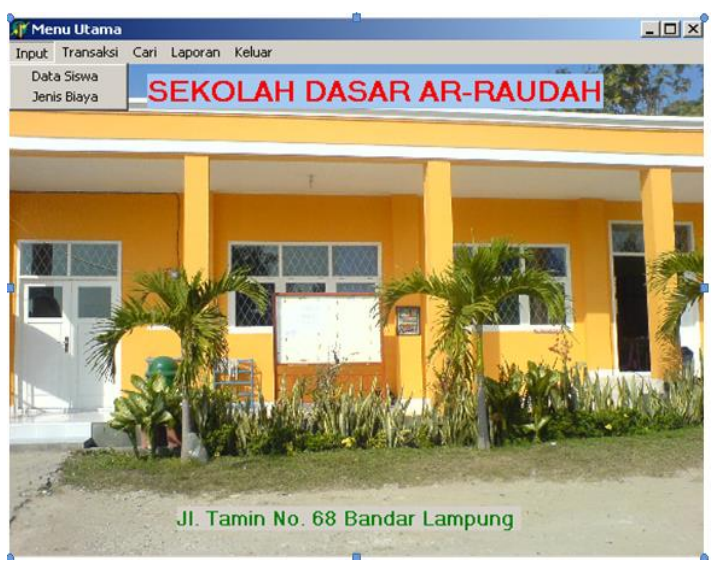

Gambar 7. Мепи Utama

\subsubsection{Menu Input Data Siswa}

Form input data siswa ini merupakan file data yang berisi data-data siswa. Form ini berfungsi untuk menginput data siswa yang kemudian akan disimpan, tampilan (layout) dari input data siswa dapat dilihat pada gambar 8 .

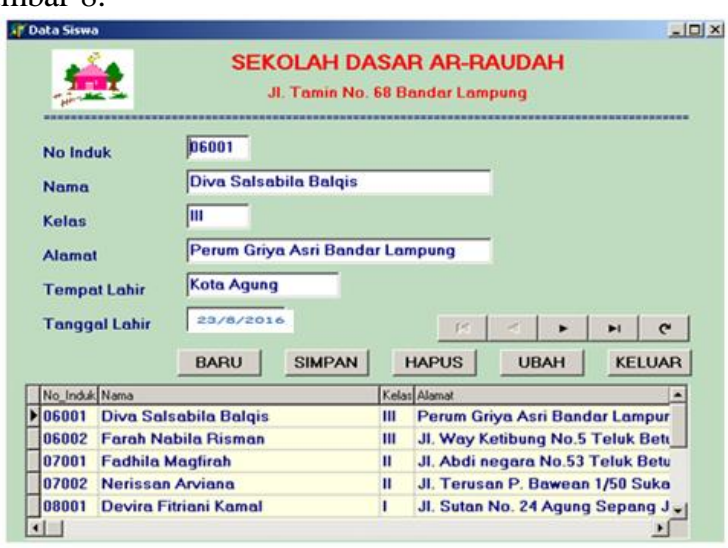

Gambar 8. Menu Input Data Siswa

\subsubsection{Menu Input Jenis Biaya}

Form input data jenis biaya ini merupakan file data yang berisi data-data jenis biaya pendidikan . Form ini berfungsi untuk menginput data jenis biaya yang kemudian akan disimpan, tampilan (layout) dari input data jenis biaya dapat dilihat gambar 9 .

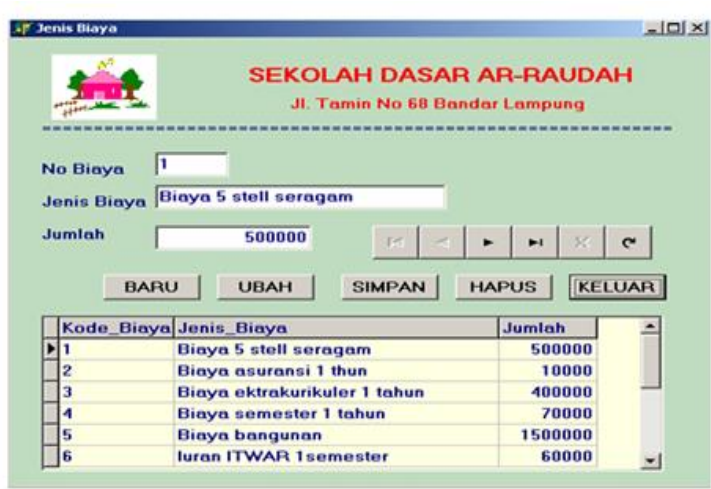

Gambar 9. Menu Input Jenis Biaya 


\subsubsection{Menu Transaksi Pembayaran}

Form transaksi pembayaran merupakan form transaksi pembayaran siswa. Form ini berfungsi untuk memasukkan data-data pembayaran yang diperoleh dari siswa, adapun tampilan (layout) dari form transaksi pembayaran siswa dapat dilihat pada gambar 10.

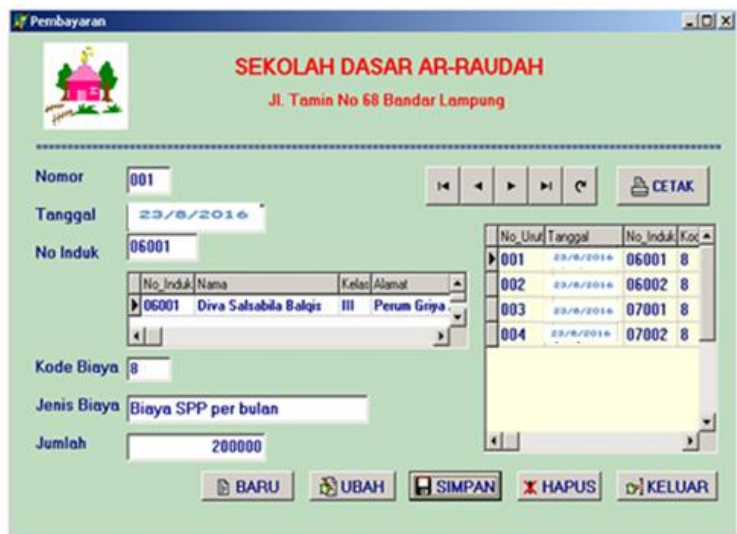

Gambar 10. Menu Transaksi Pembayaran

\subsubsection{Menu Cari Data Siswa}

Form cari data siswa merupakan form yang digunakan untuk mencari data siswa tertentu yang diinginkan. Form cari siswa terdiri dari tombol cari dan tombol keluar. Tampilan dari menu cari data siswa dapat dilihat pada gambar 11. dibawah ini:

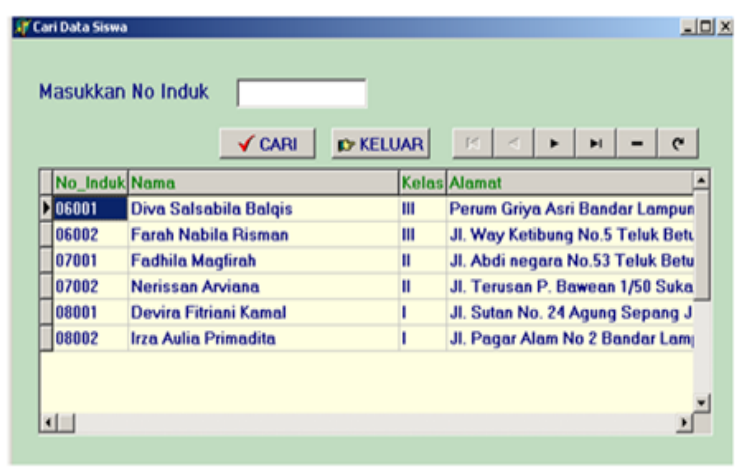

Gambar 11. Menu Cari Data Siswa

\subsubsection{Menu Cari Data Pembayaran}

Form cari data transaksi pembayaran merupakan form yang digunakan untuk mencari transaksi data pembayaran siswa tertentu yang diinginkan. Form cari transaksi pembayaran terdiri dari tombol cari dan tombol keluar. Tampilan dari menu cari transaksi pembayaran dapat dilihat pada gambar 12. dibawah ini:

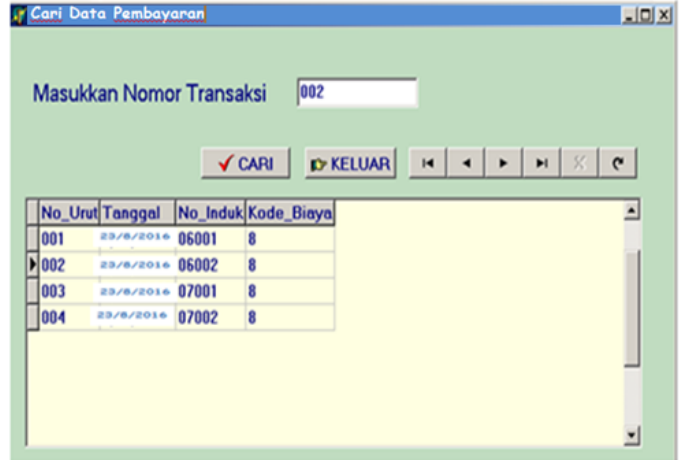

Gambar 12. Menu Cari Data pembayaran 2.3.8 Laporan Pembayaran Biaya Sekolah Pertanggal

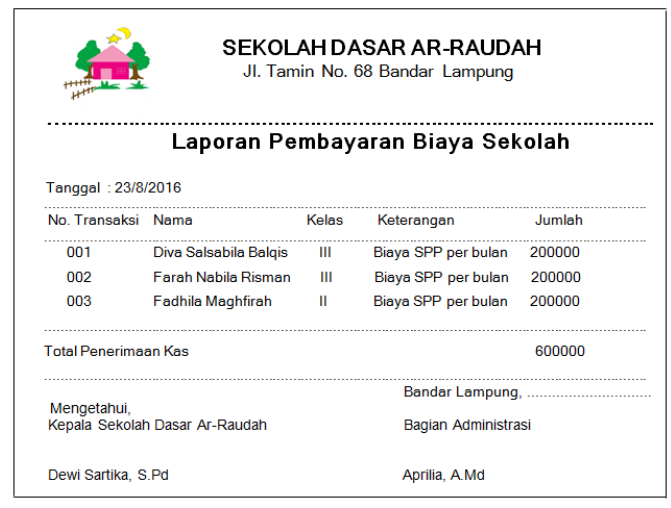

Gambar 13. Laporan Pembayara Pertanggal

\subsubsection{Laporan Pembayaran Biaya Sekolah Perbulan}

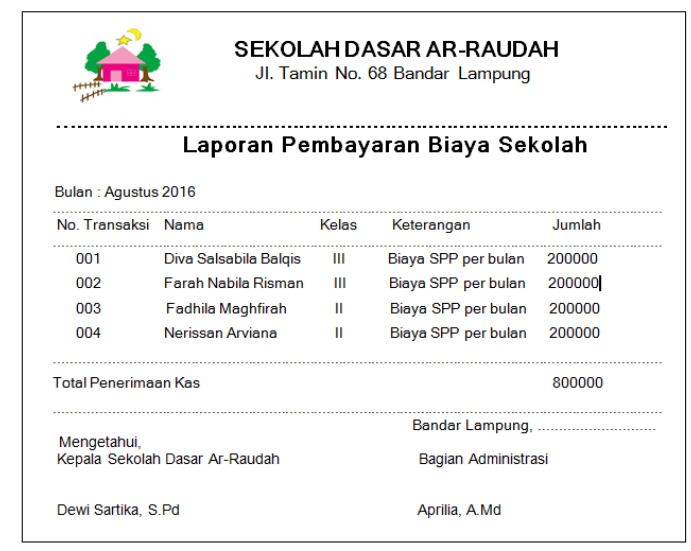

Gambar 13. Laporan Penerimaan Kas Perbulan

\section{Kesimpulan}

\subsection{Kesimpulan}

Berdasarkan pembahasan yang telah diuraikan dapat disimpulkan bahwa:

1. Sistem informasi pembayaran pada Sekolah Dasar Ar-Raudah Bandar Lampung dirancang dengan menggunakan metode pengumpulan data wawancara, observasi, studi pustaka, serta menggunakan metode pengembangan sistem 
waterfall dengan bahasa pemprograman borland delphi.

2. Sistem penerimaan kas dapat mempermudah dalam pencarian data, mempermudah dan mempercepat dalam penyajian laporan sehingga pimpinan dapat segera mengambil keputusan berdasarkan laporan yang ia terima.

3. Sistem informasi akuntansi peneriman kas telah terdapat keamanan pada sistem sehingga keamanan data dapat terjaga dari pihak yang tidak berwenang.

\subsection{Saran}

Berdasarkan penelitian dan perancangan yang telah dilakukan, maka penulis menyarankan untuk penelitian selanjutnya mengembangkan sistem informasi pembayaran biaya sekolah pada SD Arraudah Bandar Lampung berbasis web, sehingga pembayaran dapat dilakukan kapan saja dan dimana saja tanpa harus datang ke sekolah.

\section{Daftar Pustaka}

[1] Husni. Pemprograman Data Base dengan Delphi, Graha Ilmu, Malang, 2003.

[2] Jogiyanto, Analisis dan Desain Sistem Informasi, Andi Offset, Yogyakarta, 2003.

[3] Jusuf, Haryono. Dasar-Dasar Akuntansi. Sekolah Tinggi Ilmu Ekonomi YKPN, Yogyakarta, 2001.

[4] Kroenke, David M. Management Information System. Watsonville, Erlangga, Jakarta, 1992.

[5] Marlinda, L. Sistem Basis Data, Andi Offset, Yogyakarta, 2004.

[6] Novitasari dan Wardati, I.U. Pembayaran Biaya Operasional Sekolah Siswa Pada "Bank Mini Arta Prima” Sekolah Menengah Kejuruan Negeri 2 Pacitan, 2015. Indonesian Journal on Networking and Security. 2015 p. $19-24$

[7] Sutanta, E. Sistem Informasi manajemen, Graha Ilmu, Yogyakarta, 2003.

[8] Pujianto. Praktis Belajar Borland Delphi 8.0 bagi pemula, Graha Ilmu, Yogyakarta, 2007.

[9] Zainudin. Dasar-dasar Pemprogrman Visual dengan Delphi 6.0, Graha Ilmu, Yogyakarta, 2003. 